\title{
Potencial da economia de água potável pelo uso de água pluvial: análise de 40 cidades da Amazônia
}

\section{Potential for potable water savings by using rainwater: an analysis over 40 cities in Amazon}

\author{
Jeferson Alberto de Lima \\ Engenheiro Agrônomo. Mestrando em Recursos Hídricos na Universidade Federal de Mato Grosso (UFMT) \\ Marcus Vinicius Rodrigues Dambros \\ Acadêmico do curso de Engenharia Civil da Universidade Federal de Mato Grosso do Sul (UFMS) \\ Marco Antonio Peixer Miguel de Antonio \\ Acadêmico do curso de Engenharia Civil da UFMS \\ Johannes Gérson Janzen \\ Engenheiro Civil. Doutor em Hidráulica e Saneamento pela Escola de Engenharia de São Carlos da \\ Universidade de São Paulo (EESC-USP). Professor da UFMS \\ Margarida Marchetto \\ Engenheira Sanitarista. Doutora em Hidráulica e Saneamento pela EESC-USP. Professora da UFMT
}

\section{Resumo}

A escassez de água é um problema cada vez mais severo em todo o mundo devido a fatores como o consumo excessivo de água bruta, as mudanças climáticas, a poluição da água e o consumo insustentável dos recursos hídricos. Sob essas condições, formas tradicionais ou alternativas de recursos hídricos, tais como a água pluvial, estão sendo consideradas como opções atrativas para reduzir o consumo de água potável. Neste contexto, este artigo descreve o cenário de disponibilidade de água na região Amazônica, Noroeste do Brasil, e avalia o potencial da economia de água potável para o setor residencial em 40 cidades da região. Os resultados indicam que o potencial da economia de água potável varia entre 21 e 100\%, dependendo da demanda de água potável verificada nas 40 cidades, com potencial médio de $76 \%$. A principal conclusão desta pesquisa é que, se houvesse um programa do governo para promover a economia de água potável por meio da utilização da água pluvial, haveria significativa economia de água potável e, consequentemente, a preservação dos recursos hídricos na Amazônia.

Palavras-chave: água pluvial; economia; Amazônia; uso; disponibilidade.

\section{Abstract}

Water scarcity is an increasingly severe problem worldwide due to some factors, such as the excessive consumption of raw water, climate changes, water pollution, and unsustainable water resource consumption. Under these conditions, traditional or alternative forms of water resource, such as rainwater, are being considered as attractive options to reduce potable water consumption. In this context, this paper describes the water availability scenario in the Amazon region, Brazilian Northeast, and it evaluates the potential for potable water savings estimated for the residential sector of 40 cities in the region. Results indicate that the potential for potable water savings range from 21 to $100 \%$ depending on the potable water demand verified in the 40 cities, with an average potential for potable water savings of $76 \%$. The main conclusion is that if there was a government program to promote potable water savings by rainwater usage, there would be significant potable water savings and a consequent preservation of water resources in the Amazon region.

Keywords: rainwater; savings; Amazon; use; availability. 


\section{Introdução}

Nos últimos anos, o aumento da demanda por água, normalmente ocasionado pelo crescimento populacional acentuado e desordenado nos centros urbanos e pelo aumento do consumo por habitante, tem imposto a adoção de programas para conservar a água (MAY, 2004; TUCCI, 2008). Entre os componentes dos programas de conservação de água, figura-se o de substituição das fontes, que consiste basicamente em utilizar novas fontes de recursos hídricos em substituição às existentes (IPARDES, 2001). O aproveitamento de água pluvial precipitada nas residências do meio urbano se enquadra nessa categoria. Essa tecnologia vem crescendo e dando ênfase à conservação da água. Além de proporcionar economia de água potável, o aproveitamento da água pluvial em residências pode reduzir as despesas com água potável e contribuir para a diminuição do pico de inundações, quando aplicada em larga escala, de forma planejada e em uma bacia hidrográfica (TOMAZ, 2003).

Podem-se citar outros aspectos positivos no uso dos sistemas de aproveitamento de água pluvial: preservação do meio ambiente; utilização de estruturas existentes na edificação (telhado, lajes e rampas); baixo impacto ambiental; água com qualidade aceitável para vários fins, com pouco ou nenhum tratamento; aumento da segurança hídrica para atender o crescimento populacional ou para atender áreas deficientes de abastecimento; redução dos investimentos na captação da água em mananciais cada vez mais distantes das concentrações urbanas para atender a demanda diária e a de pico; redução do volume de água a ser captada e tratada e minimização do uso de água tratada para fins secundários; menor entropia, ou seja, redução dos custos energéticos de transporte e dos custos de tratamento, pois a água terá o nível de tratamento adequado a seu uso (o custo energético representa de 25 a $45 \%$ do custo total das operações de sistemas de abastecimento de água); melhor distribuição da carga de água pluvial imposta ao sistema de drenagem; redução dos riscos de enchentes, erosão dos leitos dos rios e assoreamento nas áreas planas no início da temporada de chuvas torrenciais e em eventos isolados; redução dos custos proporcionados por inundações e alagamentos; possibilidade de uso para recarga dos lençóis subterrâneos e manutenção dos níveis do lençol freático elevado (MAY, 2004; SIMIONI et al., 2004; GONÇALVES, 2006; VIOLA, 2008).

O aproveitamento de água pluvial para consumo potável em residências é um sistema utilizado há anos em países como Austrália, Alemanha, Estados Unidos e Japão (COOMBES et al., 2000; HERRMANN; SCHMIDA, 2000; ZAIZEN et al., 2000; GELT, 2009). Estudos realizados nas residências desses países indicam que a economia de água é usualmente superior a 30\%, dependendo de diversos fatores como demanda, área de telhado e precipitação. $\mathrm{O}$ Brasil, embora possua um grande potencial hídrico (11\% da água no mundo), não possui programa governamental para promover o aproveitamento da água pluvial em residências. Ademais, a abundância de água que o Brasil ainda possui e a pequena valoração econômica (a água é considerada bem de uso comum do povo) incentivam a cultura do desperdício (BRASIL, 1988; VIOLA, 2008). Assim, apesar da abundância, a disponibilidade hídrica no Brasil diminuiu, entre 1980 e 2007, em 66\% (Tabela 1), principalmente devido ao aumento populacional

A situação não é diferente na Amazônia Ocidental, região Noroeste do Brasil (Tabela 1). Esta ocupa uma área de 2.194 .599 km² (que corresponde a $25,7 \%$ do território brasileiro), possui aproximadamente 5.726.805 habitantes e se constitui dos estados de Amazonas, Acre, Rondônia e Roraima (Figura 1).

Na Figura 2, apresenta-se a distribuição de precipitação ao longo do ano nas capitais dos quatro estados que compõem a Amazônia Ocidental. É possível observar que a distribuição de precipitação ao longo do ano apresenta forte sazonalidade. Essa é uma característica típica da precipitação na região Amazônica. Outro fator que vale a pena destacar é o elevado índice de precipitação anual. A média anual de precipitação na Amazônia Ocidental varia entre 1.400 a 2.600 mm/ano.

Apesar dos elevados índices de precipitação, a disponibilidade hídrica na Amazônia Ocidental está diminuindo. O decréscimo registrado entre 1980 e 2007 foi de 43\% (Tabela 1). As principais razões para a diminuição do potencial hídrico são: a degradação dos recursos hídricos, o aumento da população e a ineficiência dos sistemas de abastecimento de água. No contexto da degradação dos recursos hídricos na Amazônia, esta se deve, entre outros fatores, aos garimpos, aos desmatamentos, ao plantio de pastagens e à produção agrícola. Com relação ao aumento da população, no período de 1970 a 2000, a população amazônica quase triplicou, evoluindo de, aproximadamente, 7,3 para 21 milhões de habitantes em decorrência das elevadas taxas anuais de crescimento experimentadas, sempre superiores à média brasileira. Finalmente, no contexto da eficiência dos serviços para abastecimento de água, um dos principais problemas diz respeito ao grande desperdício do recurso e à elevada perda de água que ocorre nos sistemas de abastecimento. Porto Velho, por exemplo, é a capital brasileira com menor cobertura de água e maior perda de água produzida (SNIS, 2007).

A disponibilidade hídrica não é a única questão que deve ser considerada na presente análise. Na realidade, a drenagem de águas pluviais é um item que tem apresentado dificuldades na Amazônia. A região Norte do Brasil continua sendo a menos favorecida com relação aos serviços de drenagem urbana. A falha da drenagem de águas pluviais tem efeitos imediatos e visíveis, o que preocupa a administração pública. Dentre as medidas que devem ser contempladas numa drenagem urbana moderna estão: a implantação de reservatórios e microreservatórios de detenção e aproveitamento de água pluvial e subsídios para produtos de aproveitamento de água pluvial (BAPTISTA; NASCIMENTO; BARRAUD, 2005). Nota-se, assim, que a drenagem urbana está diretamente relacionada com a disponibilidade hídrica. 


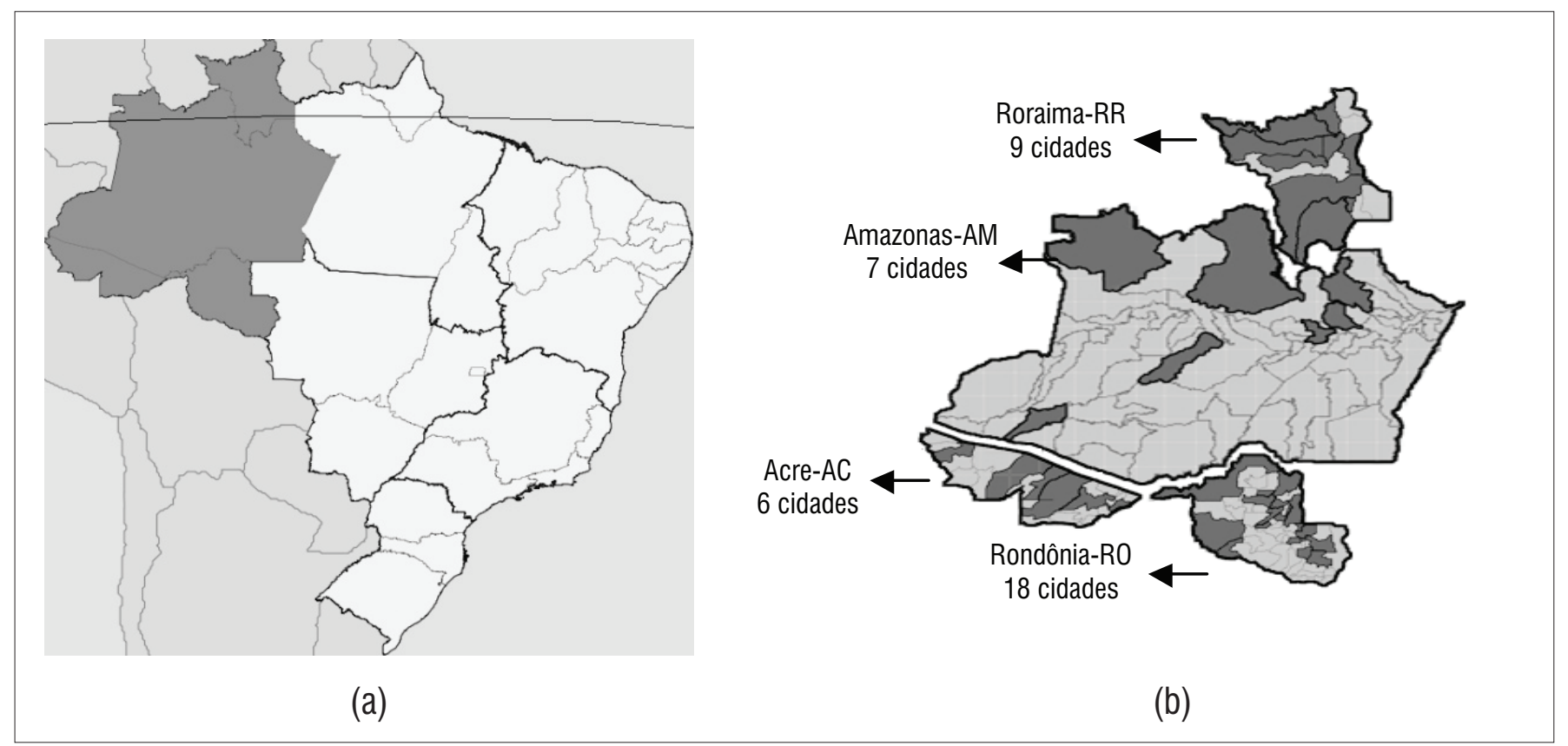

Figura 1 - (a) Mapa do Brasil com a localização da Amazônia Ocidental; (b) localização dos quatro estados da Amazônia 0cidental e das 40 cidades selecionadas para estudo do potencial de economia de água potável por meio do uso de água pluvial.

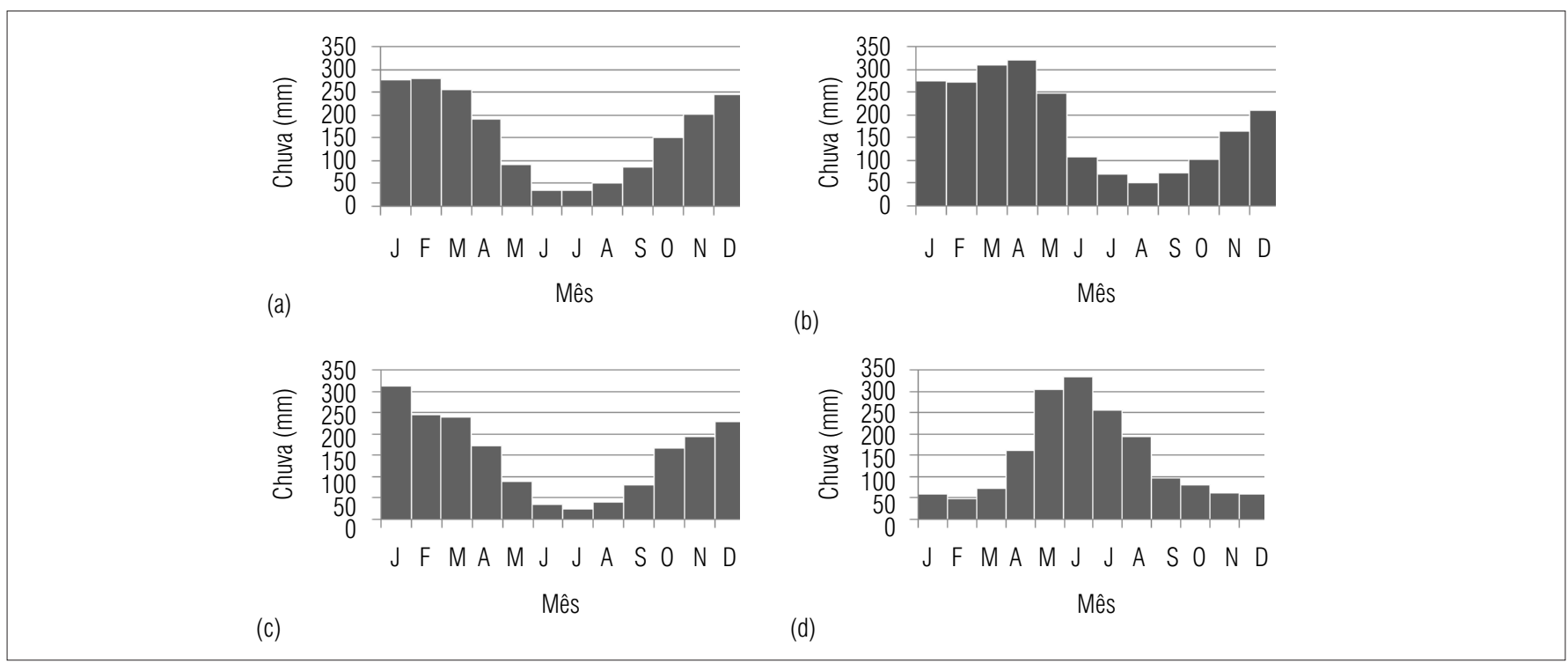

Figura 2 - Precipitação média mensal nas capitais dos quatro estados que compõem a Amazônia Ocidental do Brasil: (a) Rio Branco (Acre) - 1904 mm/ano; (b) Manaus (Amazonas) - 2207 mm/ano; (c) Porto Velho (Rondônia) - 1828 mm/ano; (d) Boa Vista (Roraima) - 1731 mm/ano.

Tal tendência de crescimento acelerado associada à diminuição do potencial hídrico e a situação preocupante da drenagem urbana são fatores primordiais para justificar a adoção dos programas de conservação de água em regiões que dispõem de recursos hídricos significativos (HESPANHOL, 2002), tais como a Amazônia Ocidental. Dentro dessa perspectiva, neste artigo, pretende-se apresentar o potencial da economia de água potável em residências da Amazônia Ocidental do Brasil, por meio do uso de água pluvial, utilizando a metodologia proposta por Ghisi et al. (2006).
Tabela 1 - Redução da disponibilidade de água na Amazônia Ocidental e no Brasil, entre 1980 e 2007 (ANA, 2009; IBGE, 2007)

\begin{tabular}{lccc}
\multicolumn{1}{c}{ Região } & \multicolumn{2}{c}{ Disponibilidade de água } & $\begin{array}{c}\text { Redução da } \\
\text { disponibilidade }\end{array}$ \\
\cline { 2 - 4 } & $\begin{array}{c}1980 \\
\left(\mathrm{~m}^{3} / \mathrm{hab} \text {. } / \mathrm{ano}\right)\end{array}$ & $\begin{array}{c}2007 \\
\left(\mathrm{~m}^{3} / \mathrm{hab} \text {. } / \mathrm{ano}\right)\end{array}$ & $\%$ \\
\hline Acre & 493245 & 234976 & 48 \\
\hline Amazonas & 1237607 & 573568 & 46 \\
\hline Rondônia & 272483 & 103181 & 38 \\
\hline Roraima & 4037422 & 940047 & 23 \\
\hline Amazônia Ocidental & 1030714 & 440734 & 43 \\
\hline Brasil & 47142 & 31160 & 66
\end{tabular}




\section{Metodologia}

Para o cálculo do potencial de aproveitamento da água pluvial, seguindo a metodologia apresentada por Ghisi et al. (2006), são necessários dados de precipitação, população atendida por serviço de abastecimento de água, consumo de água potável, população, número de domicílios e porcentagem das casas e apartamentos para cada uma das cidades selecionadas. Não foi possível incluir todas as cidades da Amazônia Ocidental, pois apenas 40 delas apresentam os dados requeridos (6 no Acre; 7 no Amazonas; 18 em Rondônia e 9 em Roraima). Na Tabela 2 são apresentadas as cidades escolhidas. $\mathrm{Na}$ Figura 1 são indicadas as localizações das 40 cidades selecionadas. Os próximos itens evidenciam os detalhes da metodologia apresentada por Ghisi et al. (2006).

\section{Dados de precipitação}

Os dados mensais de precipitação, obtidos pela Agência Nacional de Água (ANA, 2009), não cobrem o mesmo período para todas as cidades. Ademais, algumas séries históricas são incompletas. Os dados foram processados para obtenção da precipitação média mensal em cada cidade. Ressalta-se que o sucesso dos sistemas de aproveitamento de água pluvial depende da distribuição e regularidade das precipitações (PETERS, 2006).

\section{Volume de chuva}

Os itens a seguir evidenciam os detalhes do cálculo do potencial de volume de chuva a ser coletado em cada uma das cidades.

Tabela 2 - Relação das cidades selecionadas na Amazônia Ocidental para estudo do potencial de economia de água potável pelo uso de água pluvial

\begin{tabular}{|llll}
\hline Número & Cidade/Estado & Número & Cidade/Estado \\
\hline 01 & Ariquemes/RO & 21 & Manoel Urbano/AC \\
\hline 02 & Cacoal/RO & 22 & Plácido de Castro/AC \\
\hline 03 & Candeias do Jamari/RO & 23 & Rio Branco/AC \\
\hline 04 & Chupinguaia/RO & 24 & Sena Madureira/AC \\
\hline 05 & Costa Marques/RO & 25 & Barcelos/AM \\
\hline 06 & Guajará-mirim/RO & 26 & Eirunepé/AM \\
\hline 07 & Jaru/RO & 27 & Manacapuru/AM \\
\hline 08 & Ji-Paraná/RO & 28 & Manaus/AM \\
\hline 09 & Machadinho D'Oeste/RO & 29 & Presidente Figueiredo/AM \\
\hline 10 & Ministro Andreazza/RO & 30 & São Gabriel da Cachoeira/AM \\
\hline 11 & Mirante da Serra/RO & 31 & Tefé/AM \\
\hline 12 & Ouro Preto do Oeste/RO & 32 & Alto Alegre/RR \\
\hline 13 & Parecis/RO & 33 & Amajari/RR \\
\hline 14 & Pimenta Bueno/RO & 34 & Boa Vista/RR \\
\hline 15 & Porto Velho/RO & 35 & Bonfim/RR \\
\hline 16 & Rio Crespo/RO & 36 & Caracaraí/RR \\
\hline 17 & Rolim de Moura/RO & 37 & Mucajaí/RR \\
\hline 18 & Theobroma/RO & 38 & Pacaraima/RR \\
\hline 19 & Cruzeiro do Sul/AC & 39 & Rorainópolis/RR \\
\hline 20 & Feijó/AC & 40 & São Luiz/RR \\
\hline
\end{tabular}

População atendida pelo serviço de abastecimento de água

O número de pessoas atendidas pelo serviço de abastecimento de água em cada cidade foi obtido do Sistema Nacional de Informação sobre Saneamento - SNIS (SNIS, 2007).

\section{Número de pessoas por domicílio}

A população (PC) e o número de domicílios (NDC) de cada cidade foram obtidos pelo Instituto Brasileiro de Geografia e Estatística - IBGE (IBGE, 2007). A partir dessas informações, é possível calcular o número de pessoas por domicílio (PD), por meio da Equação 1:

$P D=\frac{P C}{N D C}$

Equação 1

\section{Número de domicílios abastecidos pelo serviço de água}

O número de pessoas atendidas pelo serviço de abastecimento de água (NP) foi obtido a partir do SNIS (SNIS, 2007). O número de domicílios abastecidos pelo serviço de água (ND) pode ser estimado por meio da Equação 2:

$N D=\frac{N P}{P D}$

Equação 2

\section{Área total do telhado}

Não há informações oficiais sobre a área de telhados para a região da Amazônia Ocidental do Brasil. Por conseguinte, a área de telhados considerada será igual à de Ghisi et al. (2006): $85 \mathrm{~m}^{2}$ para casas e $3,75 \mathrm{~m}^{2}$ por pessoa para apartamentos. Com esses dados e a porcentagem de casas e apartamentos, é possível obter a área média ponderada do telhado por meio da Equação 3:

$R A=H \cdot 85+F \cdot P D \cdot 3,75$

Equação 3

onde:

RA: área média ponderada do telhado por domicílio em cada cidade $\left(\mathrm{m}^{2}\right)$;

$H$ : porcentagem de casas em cada cidade;

F: porcentagem de apartamentos em cada cidade.

A área total do telhado em cada cidade (TRA) (m²), considerando-se somente a população atendida pelo serviço de água, pode ser calculada por meio da Equação 4:

$T R A=R A \cdot N D$

Equação 4

\section{Volume de chuva}

O volume de chuva, que poderia ser coletado em cada cidade, foi determinado considerando os dados de precipitação mensais, a 
área total do telhado e o coeficiente de runoff igual a 0,8. Este coeficiente indica que $20 \%$ da água pluvial é perdida pelo descarte para a limpeza do telhado e da evaporação. Assim, o volume de chuva que poderia ser coletado é igual a:

$V R=\frac{R \cdot T R A \cdot R_{C}}{1000}$

onde:

VR: volume mensal de chuva que poderia ser coletado em cada cidade ( $\left.\mathrm{m}^{3} / \mathrm{mês}\right)$;

R: precipitação média mensal (mm/mês);

TRA: área total em cada cidade $\left(\mathrm{m}^{2}\right)$;

Rc: coeficiente de runoff;

1.000: fator de conversão de litros para $\mathrm{m}^{3}$

\section{Consumo de água potável}

O consumo de água potável foi obtido do SNIS (SNIS, 2007).

\section{Potencial de economia de água potável}

O potencial mensal de economia de água potável foi determinado para cada uma das 40 cidades usando a Equação 6:

$P P W S=100 \frac{V R}{P W R}$ Equação 6

onde:

PPWS: potencial de economia de água potável em cada cidade (\%); PWR: consumo de água potável mensal em cada cidade ( $\left.\mathrm{m}^{3} / \mathrm{mês}\right)$.

\section{Resultados}

\section{Número de pessoas por domicílio}

O número de pessoas por domicílio, nas 40 cidades, encontra-se entre 2,91 e 5,68, com média igual a 3,61 pessoas por domicílio. Este valor está um pouco abaixo da média da região Norte do Brasil (3,9 pessoas por domicílio) (IBGE, 2007). Os estados que apresentaram o maior e o menor número de pessoas por domicílio foram, respectivamente, Amazonas e Rondônia. Na Figura 3 é apresentada a média de pessoas por domicílio nas 40 cidades analisadas.

\section{Área do telhado}

Segundo Ghisi et al. (2006), para determinar adequadamente a área do telhado por domicílio, é necessário obter as porcentagens das casas e dos apartamentos para cada cidade. Nos apartamentos, a área de telhado por pessoa é inferior à das casas, já que concentram-se mais pessoas em uma mesma área.
A Figura 4 apresenta a porcentagem de casas e apartamentos e a área média do telhado nas 40 cidades. A porcentagem média de casas e apartamentos para todas as cidades é igual a 98,1 e 1,9\%, respectivamente. Somente Manaus, capital do estado do Amazonas, cidade com a maior população entre as 40 cidades estudadas, com aproximadamente 1,6 milhões de habitantes, possui porcentagem de apartamentos mais alta que as demais (maior que 10\%). Tais valores de porcentagem de casas são maiores do que os obtidos em estudo similar realizado no Estado de Santa Catarina (GHISI et al., 2006). Ghisi et al. (2006) obtiveram porcentagem média de casas igual a 96\%.

A área média do telhado por domicílio para as 40 cidades, que foi obtida por meio da Equação 3, foi de 83,67 m², variando entre 79,78 a $84,84 \mathrm{~m}^{2}$. Novamente, a exceção foi Manaus com $77,41 \mathrm{~m}^{2}$.

\section{Consumo de água potável}

Na Figura 5, mostra-se o consumo de 36 das 40 cidades avaliadas, com exceção da cidade de Barcelos, Manacapuru; São Gabriel da Cachoeira, no Estado do Amazonas; e Chupinguaia, no estado de Rondônia, que não apresentam dados de consumo per capita. A média do consumo de água por cidade é de aproximadamente $102 \mathrm{~L}$

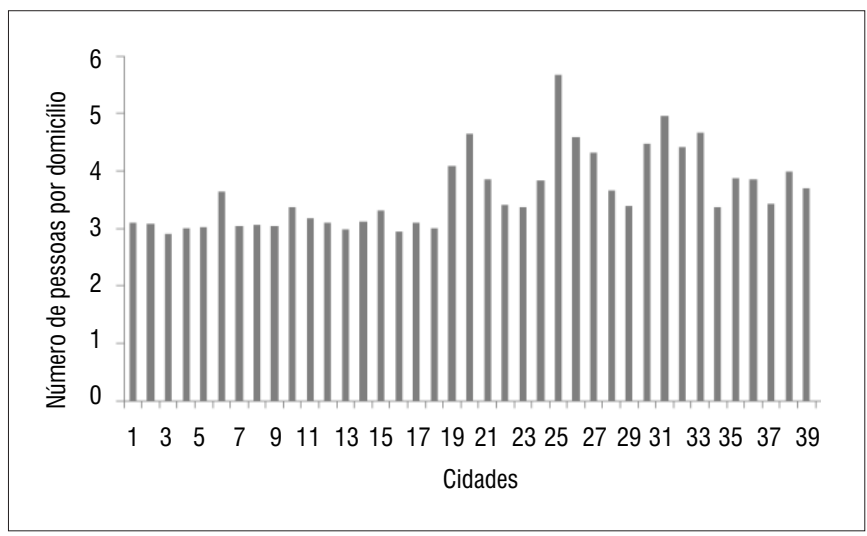

Figura 3 - Número médio de pessoas por domicílio nas 40 cidades selecionadas na Amazônia Ocidental (IBGE, 2007). A numeração das cidades encontra-se na Tabela 2.

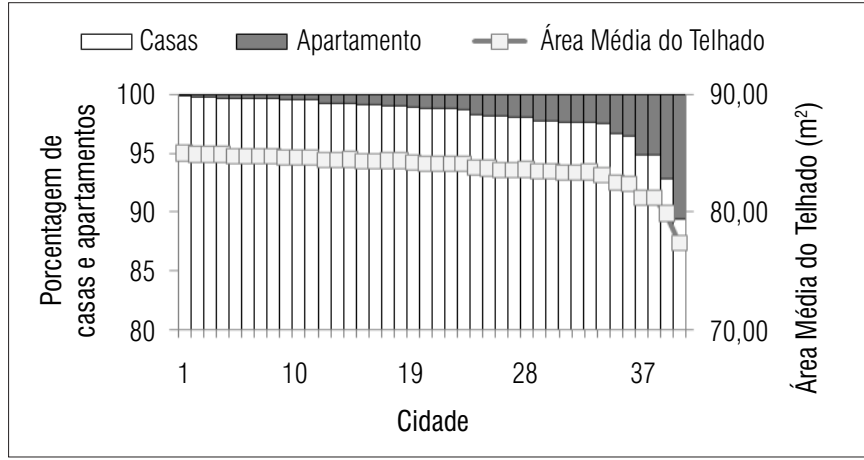

Figura 4 - Porcentagem de casas e apartamentos e área média do telhado nas 40 cidades da Amazônia Ocidental (IBGE, 2007). A numeração das cidades encontra-se na Tabela 2. 
per capita por dia, variando entre $48 \mathrm{~L} / \mathrm{hab} . / \mathrm{dia}$, em Costa Marques, Rondônia, e 213 L/hab./dia, em Cacoal, Rondônia.

\section{Volume de precipitação}

O volume de precipitação que poderia ser coletado foi calculado conforme descrito na Metodologia. Na Tabela 3 são apresentados os resultados obtidos para Manaus.

\section{Potencial de economia de água potável}

Na Figura 6, apresenta-se o potencial de economia de água potável para todas as cidades. Nota-se que o potencial de economia de água varia entre 21 e 100\%. A cidade de Rorainópolis (RR) é a única que obteve potencial de $100 \%$ para todos os meses, enquanto Manacapuru (AM) não obteve valores superiores a 35\%. Tais valores são similares aos obtidos em estudos nas regiões Sudeste e Sul do Brasil (BRESSAN; MARTINI, 2005; GHISI et al., 2006).

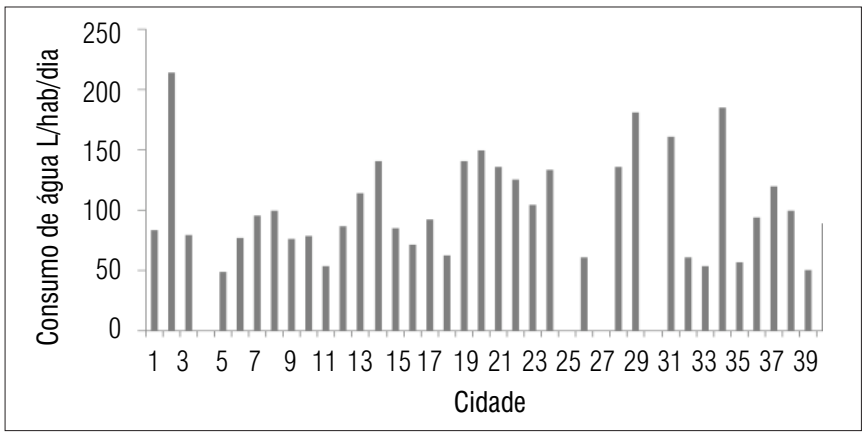

Figura 5 - Volume de água potável consumido diariamente por habitante em 36 cidades da Amazônia Ocidental (SNIS, 2007). A numeração das cidades encontra-se na Tabela 2.

Tabela 3 - Volume de precipitação que poderia ser coletado na cidade de Manaus/AM calculado conforme descrito na seção "Metodologia" (SNIS, 2007; ANA, 2009; IBGE, 2007)

\begin{tabular}{|c|c|c|c|c|c|c|c|}
\hline$\sum_{\substack{\infty \\
\Sigma}}^{\infty}$ & 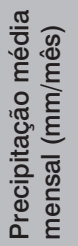 & 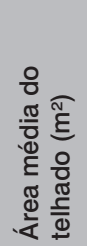 & 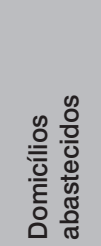 & 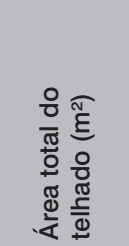 & 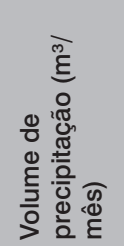 & 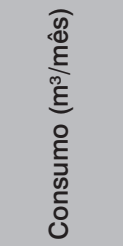 & $\begin{array}{l}\frac{0}{0} \\
\frac{0}{0} \\
\frac{\pi}{0} \\
\frac{\pi}{\varepsilon} \\
\frac{0}{0} \\
\frac{0}{0} \\
0 \\
0\end{array}$ \\
\hline Jan. & 275 & 77,41 & 403549 & 31236751 & 6865652 & 5984637 & 100 \\
\hline ev. & 271 & 77,41 & 403549 & 31236751 & 6771277 & 5984637 & 100 \\
\hline Mar. & 308 & 77,41 & 403549 & 31236751 & 7695991 & 5984637 & 100 \\
\hline Abr. & 320 & 77,41 & 403549 & 31236751 & 7998735 & 5984637 & 100 \\
\hline Mai. & 248 & 77,41 & 403549 & 31236751 & 6196804 & 5984637 & 100 \\
\hline Jun. & 108 & 77,41 & 403549 & 31236751 & 2699942 & 5984637 & 45 \\
\hline Jul. & 71 & 77,41 & 403549 & 31236751 & 1772812 & 5984637 & 30 \\
\hline Ago. & 53 & 77,41 & 403549 & 31236751 & 1320418 & 5984637 & 22 \\
\hline Set. & 74 & 77,41 & 403549 & 31236751 & 1844430 & 5984637 & 31 \\
\hline Out. & 104 & 77,41 & 403549 & 31236751 & 2587413 & 5984637 & 43 \\
\hline Jov. & 165 & 77,41 & 403549 & 31236751 & 4123305 & 5984637 & 69 \\
\hline ez. & 211 & 77,41 & 403549 & 31236751 & 5273198 & 5984637 & 88 \\
\hline
\end{tabular}

Na Figura 7, apresenta-se o potencial de economia máximo, médio e mínimo, observado em cada mês para todas as cidades. Vale a pena observar que o potencial de economia máximo é sempre igual a 100\%. O valor mínimo varia entre 3\% (em junho, período mais crítico da seca) e 21\% (dezembro). A média geral é de 76\%, superior àquela obtida por Ghisi et al. (2006) para o Estado de Santa Catarina (69\%). É interessante observar, entretanto, que a variabilidade do potencial de aproveitamento na Amazônia Ocidental é bem maior do que no Sul do Brasil. Conforme já mencionado, isso é decorrente da existência na Amazônia de duas estações bem definidas: uma chuvosa e outra seca. Na estação chuvosa, o potencial de aproveitamento é de $100 \%$. Já na estação seca é comum ter meses em que a precipitação e o aproveitamento de água pluvial são próximos de zero.

O consumo de água tratada para fins não-potáveis em residências no Brasil é usualmente inferior a 50\% (BRESSAN; MARTINI, 2005). Nota-se, na Figura 7, que 95\% das cidades analisadas apresentaram potencial de economia de água superior a 50\%. No Sudeste, a porcentagem de municípios com potencial médio de economia de água acima de 50\% encontra-se entre 15,6 e 39,2\% (BRESSAN; MARTINI, 2005). Observa-se, assim, que o potencial da região Amazônica é bem superior ao do Sudeste do Brasil. Portanto, é possível substituir praticamente todo o consumo de água tratada para fins não-potáveis com água pluvial.

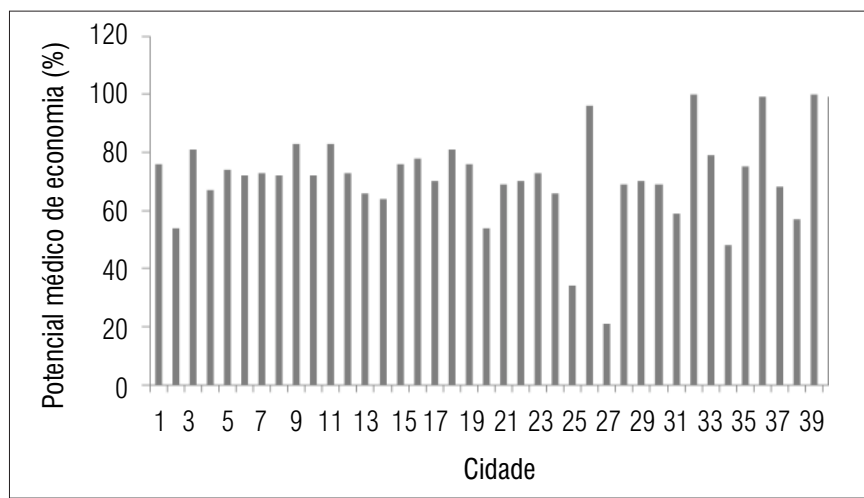

Figura 6 - Potencial médio de economia de água das 40 cidades analisadas. A numeração das cidades encontra-se na Tabela 2.



Figura 7 - Máximo, médio e mínimo potencial de economia de água potável para as 40 cidades. 
O potencial de economia de água potável das cidades capitais dos quatro estados que compõem a Amazônia Ocidental (Rio Branco - AC, Manaus - AM, Porto Velho - RO e Boa Vista - RR), é apresentado na Figura 8. Novamente, é possível observar o efeito da sazonalidade das chuvas no potencial de economia de água. Porto Velho, em Rondônia, é a cidade que se destaca com o maior potencial de economia de água entre as quatro capitais, pois os valores máximos de potencial da economia de água são atingidos em 7 dos 12 meses do ano.

A Figura 9 apresenta o potencial médio de economia de água potável para os quatro estados. Os estados com melhor e pior potencial são, respectivamente, Roraima e Amazonas.

Conclui-se que a Amazônia Ocidental não tem um volume mensal de chuva suficiente para atender toda a demanda residencial de água. Porém, isso não inviabiliza o investimento, nem diminui as vantagens já mencionadas oriundas da adoção de programas de conservação de água.

\section{Conclusão}

Neste estudo, investigou-se o problema da escassez de água e do potencial de economia de água por meio do uso de água pluvial na Amazônia Ocidental, no Brasil. Os resultados mostram que a disponibilidade de água está diminuindo rapidamente devido à degradação dos recursos hídricos e ao aumento da população. Dessa forma, apesar da abundância hídrica, a Amazônia Ocidental pode futuramente enfrentar problemas caso não haja um programa do Governo para promover a conservação da água.

Os resultados obtidos por meio de pesquisa realizada em 40 cidades da Amazônia Ocidental mostram excelente precipitação média anual na região, a saber, $2.002 \mathrm{~mm}$. A média do potencial de economia de água potável estimado para as 40 cidades é de $76 \%$, variando entre 21 e 100\%, dependendo essencialmente do consumo e da área total do telhado. Nota-se o potencial de utilização da água pluvial

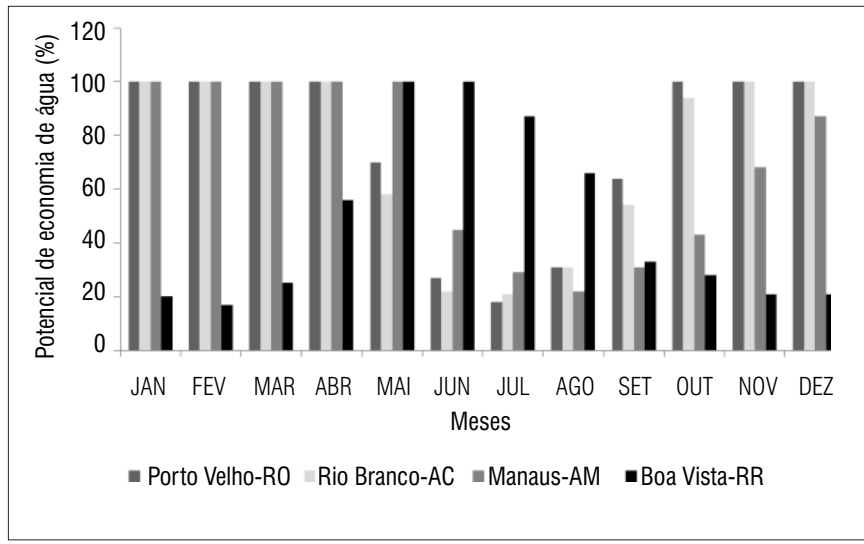

Figura 8 - Potencial da economia de água das capitais dos estados da Amazônia Ocidental.

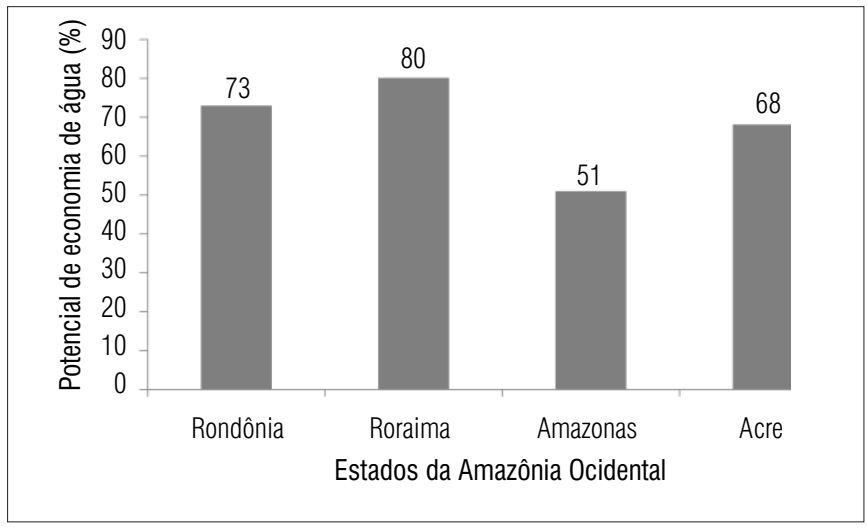

Figura 9 - Média do potencial da economia de água dos quatro estados da Amazônia Ocidental.

como fonte hídrica alternativa para uso residencial. Devido à região Amazônica possuir duas estações bem definidas, uma chuvosa e outra seca, verificou-se que, na chuvosa, o potencial de aproveitamento alcança 100\%. No entanto, na estação seca, com meses sem precipitação, o aproveitamento de água pluvial ainda é bastante baixo.

\section{Referências}

AGÊNCIA NACIONAL DE ÁGUAS - ANA. Sistema de Informações Hidrológicas. 2009. Disponível em <http://hidroweb.ana.gov.br>. Acessado em julho de 2009.

BAPTISTA, M.; NASCIMENTO, N.; BARRAUD, S. Técnicas compensatórias em drenagem urbana. 1 ed. Porto Alegre, RS: Ed. Universidade / UFRGS - ABRH, 2005.

BRASIL. Senado Federal. Constituição da República Federativa do Brasil. Brasília: Senado Federal, 1988.

BRESSAN, D.L.; MARTINI, M. Avaliação do potencial de economia de água tratada no setor residencial da região sudeste através do aproveitamento de água pluvial. Trabalho de Conclusão de Curso - Universidade Federal de Santa Catarina, Florianópolis, 2005. $117 p$.

COOMBES P.J.; ARGUE J.R.; KUCZERA G. Figtree place: a case study in water sensitive urban development (WSUD). Urban Water, v. 1, n. 4, p. 335-343, 2000.

GHISI, E.; MONTIBELLER, A.; SCHMIDT, R.W. Potential for potable water savings by using rainwater: an analysis over 62 cities in southern Brazil. Building and Environment, v. 41, n. 2, p. 204-210, 2006. 
GONÇALVES, R. F. (Coord.). Uso Racional da Água em Edificações. 1 ed. Vitória, ES: ABES, 2006

HERRMANN, T.; SCHMIDA, U. Rainwater utilization in Germany: efficiency, dimensioning, hydraulic and environmental aspects. Urban Water, v. 1, n. 4, p. 307-316, 2000.

HESPANHOL, I. Potencial de reuso de água no Brasil. Agricultura, indústria, municípios, recarga de aquíferos. Revista Brasileira de Recursos Hídricos, v. 7, n. 4, p. 75-95, 2002.

INSTITUTO BRASILEIRO DE GEOGRAFIA E ESTATÍSTICA - IBGE. Contagem da população, 2007. Disponível em <http://www.ibge.gov. br>. Acesso em julho de 2009.

INSTITUTO PARANAENSE DE DESENVOLVIMENTO ECONÔMICO E SOCIAL. Agenda 21. Conferencia das Nações Unidas sobre Meio Ambiente e Desenvolvimento. Curitiba: Instituto Paranaense de Desenvolvimento Econômico e social - IPARDES, 2001. 260p.

GELT, J. Home Use of Graywater, Rainwater Conserves Water and May Save Money. Disponível em <http://ag.arizona.edu/azwater/ arroyo/071rain.html>. Acesso em julho de 2009.

MAY, S. Estudo da Viabilidade do Aproveitamento de Água de Chuva para Consumo Não Potável em Edificações. Dissertação (Mestrado em Engenharia da Construção Civil) - Escola Politécnica da Universidade de São Paulo, São Paulo, 2004. 189p.
PETERS, M. R. Potencialidade de uso de fontes alternativas de água para fins não potáveis em uma unidade residencial. 2006. 109f. Dissertação (Mestrado em Engenharia Ambiental) - Universidade Federal de Santa Catarina, Florianópolis, 2006.

SIMIONI, W. I.; GHISI, E.; GÓMEZ L. A. Potencial de Economia de Água Tratada Através do Aproveitamento de Águas Pluviais em Postos de Combustíveis: Estudos de Caso. CLACS' 04 - I Conferência LatinoAmericana de Construção Sustentável e ENTAC 04, $10^{\circ}$ Encontro Nacional de Tecnologia do Ambiente Construído, São Paulo - SP, Anais.... CD Rom, 2004.

SISTEMA NACIONAL DE INFORMAÇÕES SOBRE SANEAMENTO SNIS. Diagnóstico dos Serviços de Água e Esgoto. 2007. Disponível em $<$ http://www.snis.gov.br>. Acesso em julho de 2009.

TOMAZ, P. Aproveitamento de Água de Chuva. 1 ed. São Paulo: Navegar 2003. $183 p$

TUCCI, C.E.M. Águas urbanas. Estudos Avançados, v. 22, n. 63, p. 97112,2008

VIOLA, H. Gestão de águas pluviais em áreas urbanas: o estudo de caso da cidade do Samba. Dissertação (Mestrado em Engenharia) Universidade Federal do Rio de Janeiro, Rio de Janeiro, 2008. 384p.

ZAIZEN, M. et al. The collection of rainwater from dome stadiums in Japan. Urban Water, v. 1, n. 4, p. 335-359, 2000 